\title{
Photos in Pediatrics
}

\section{Green nail syndrome}

\author{
Giovanni Corsello and Davide Vecchio \\ Department of Sciences for Health Promotion and Mother and Child Care, Pediatric Unit, University of Palermo, \\ Palermo, Italy
}
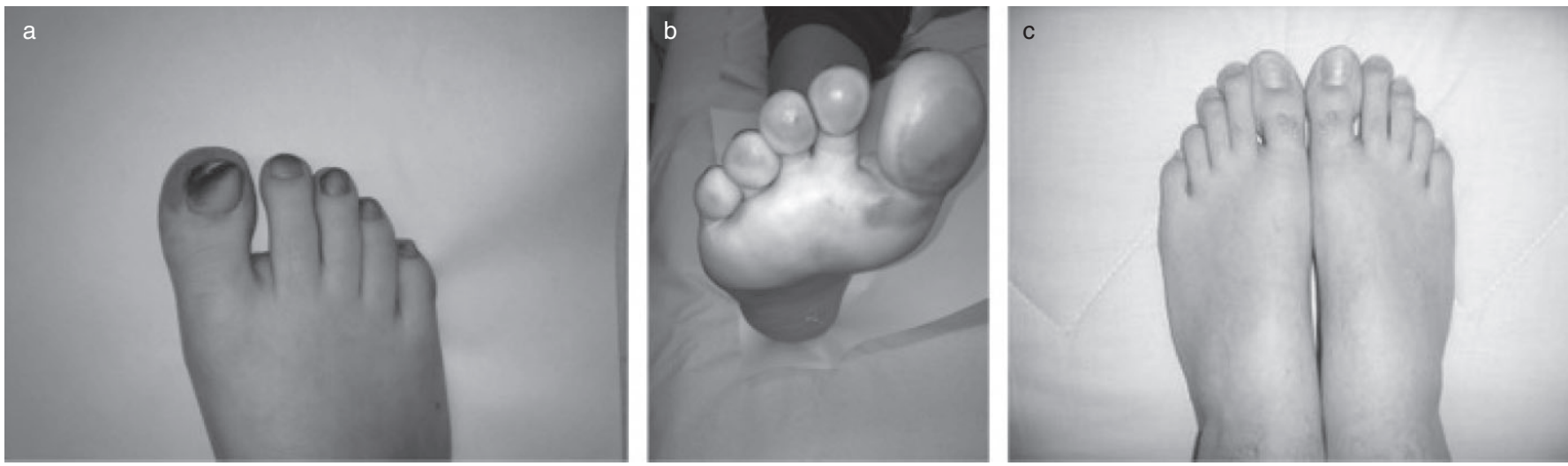

Fig. 1 (a) Green discoloration of the right toenails; (b) edudative/erythematous skin lesions; (c) after 5 weeks of treatment.

A 8-year-old boy with HIV infection due to perinatal exposure was admitted to the Pediatric Department because of green discoloration of the right toenails (Fig. 1a). Exudative/erythematous skin lesions on the lower surface at sites of pressure burden, and probably co-generated by the extensive use of unventilated athletic shoes, were also noted (Fig. 1b). At the time of diagnosis the patient was under combined antiretroviral therapy: CD4 cell count was 576 cells $/ \mu \mathrm{L}$ and HIV-RNA was $>100000$ copies $/ \mathrm{mL}$. ${ }^{1}$ Mycological examination of the affected nail scrapings was done, and fungal infection was excluded on microscopy and culture. Bacteriology indicated Pseudomonas aeruginosa on Gram stain and culture of the exudate and ungual fragments. Green nail syndrome is a paronychial infection caused by $P$. aeruginosa, a Gram-negative bacterium. ${ }^{2}$ This condition clinically presents as a greenish-black, greenish-brown or greenish-yellow discoloration of the nail. Furthermore $P$. aeruginosa has a characteristic sweet, fruity odor due to its production of trimethylamine and pyocyanin, a greenish-blue pigment that diffuses into the underside of the nail plate, accounting for the green discoloration

Correspondence: Davide Vecchio, MD, Department of Sciences for Health Promotion and Mother and Child Care, Pediatric Unit, University of Palermo, via Alfonso Giordano, 3, 90127 Palermo, Italy. Email: davide.vecchio@unipa.it

Received 10 April 2014; revised 22 June 2014; accepted 15 July 2014. characteristic of this condition. ${ }^{2,3}$ Although commonly seen, the treatment for this disorder remains challenging, and is quite complex in HIV infection, due to the lack of controlled studies assessing systemic or topical treatments. ${ }^{4,5}$ Based on immunological status, the patient was treated topically with neomycin/ polymyxin B galenic unguentum applied twice daily, rubbing it gently onto the affected nails and the surrounding skin. Complete resolution was achieved within 5 weeks (Fig. 1c).

\section{References}

1 Panel on Antiretroviral Therapy and Medical Management of HIVInfected Children. Guidelines for the Use of Antiretroviral Agents in Pediatric HIV Infection. [Cited 30 December 2013.] Available at: http://aidsinfo.nih.gov/contentfiles/lvguidelines/pediatricguidelines .pdf

2 Hengge UR, Bardeli V. Green nails. N. Engl. J. Med. 2009; 360: 1125 .

3 Tosti A, Piraccini BM. Biology of nails and nail disorders. In: Wolff K, Goldsmith L, Katz S, Gilchrest B, Paller A, Leffell D (eds). Fitzpatrick's Dermatology in General Medicine, 7th edn. McGrawHill, New York, 2008; 778-94.

4 Rallis E, Paparizos V, Flemetakis A, Katsambas A. Pseudomonas fingernail infection successfully treated with topical nadifloxacin in HIV-positive patients: Report of two cases. AIDS 2010; 24: 1087-8.

5 Rigopoulos D, Rallis E, Gregoriou S et al. Treatment of pseudomonas nail infections with $0.1 \%$ octenidine dihydrochloride solution. Dermatology 2009; 218: 67-8. 